\title{
Komunikasi Pemasaran Pengrajin Bambu Kreatif di Tasikmalaya
}

\author{
Santi Susanti ${ }^{1}$, Iwan Koswara ${ }^{2} \&$ Rachmaniar $^{3}$ \\ ${ }_{1,2,3}^{1}$ Fakultas Ilmu Komunikasi, Universitas Padjadjaran \\ E-mail: ${ }^{1}$ santi.susanti@unpad.ac.id, ${ }^{2}$ iwan.koswara@unpad.ac.id, ${ }^{3}$ rachmaniar@unpad.ac.id
}

Received: June 2021; Accepted: October 2021; Published: December 2021

\begin{abstract}
Tasikmalaya known as the centers of bamboo handicraft industry in West Java. It produces various products, from daily household equipment in the form of rough woven with low prices to creative bamboo products with high prices for the upper middle market. Products are distributed for domestic needs and demand of foreign buyers. This study reveals the marketing communication behavior of creative bamboo entrepreneurs in Tasikmalaya in developing a creative bamboo craft business. A qualitative method with a case study approach was used to obtain information about the behavior of bamboo handicraft entrepreneurs in Tasikmalaya in marketing their products. Data were collected through in-depth interviews with creative bamboo entrepreneurs who still actively running their businesses and willing to provide information about the businesses they are running. Data were also collected through non-participatory observations at the location and conducted a literature review and documents related to the research. Data analysis, data checking and validity of the data were conducted through Miles and Huberman's interactive data analysis concept. The results showed that the communication behavior conducted by creative bamboo entrepreneurs consisted of internal communication behavior and external communication behavior. Internal communication behavior is conducted on workers with the principle of kinship. Humanist approach is used to maintain production stability.The form of external communication behavior is tailored to whom they're being faced. Face-to-face communication and mediated communication are used in marketing bamboo handicraft products.
\end{abstract}

Keywords: Communication behavior; marketing communication; creative bamboo; local wisdom

\begin{abstract}
Abstrak
Abstrak

Tasikmalaya merupakan salah satu pusat industri kerajinan bambu di Jawa Barat. Produk yang dihasilkan beragam. Mulai dari perlengkapan rumah tangga sehari-hari yang masih berupa anyaman kasar dengan harga jual yang murah hingga kreasi bambu kreatif yang memiliki harga jual yang tinggi untuk pangsa pasar menengah ke atas. Produk yang dihasilkan pun diminati pembeli dari dalam dan luar negeri. Penelitian ini bertujuan mengungkapkan perilaku komunikasi pelaku usaha kerajinan bambu kreatif di Tasikmalaya dalam mengembangkan bisnis lokal berorientasi pasar lokal, nasional dan ekspor. Metode kualitatif dengan pendekatan studi kasus digunakan untuk menggali informasi mengenai perilaku pelaku usaha kerajinan bambu di Tasikmalaya dalam memasarkan produknya. Data dikumpulkan melalui wawancara mendalam kepada para pelaku usaha bambu kreatif yang masih aktif menjalani usaha serta bersedia memberikan informasi mengenai bisnis yang dijalaninya. Data pun dikumpulkan melalui observasi nonpartisipatif di lokasi serta melakukan kajian pustaka dan literatur yang terkait penelitian. Analisis, pengecekan serta validitas data dilakukan melalui konsep analisis data interaktif Miles dan Huberman. Hasil penelitian menunjukkan, perilaku komunikasi yang dijalankan para pelaku usaha bambu kreatif di terdiri dari perilaku komunikasi internal dan perilaku komunikasi eksternal. Perilaku komunikasi internal dilakukan kepada para pekerja dengan prinsip kekeluargaan. Pendekatan humanis digunakan untuk menjaga kestabilan produksi. Sementara itu, bentuk perilaku komunikasi eksternal disesuaikan dengan pihak yang dihadapi. Komunikasi tatap muka dan komunikasi melalui media digunakan dalam memasarkan produk kerajinan bambu.
\end{abstract}

Kata kunci: Perilaku komunikasi; komunikasi pemasaran; bambu kreatif; kearifan lokal.

doi: https://doi.org/10.51544/jlmk.v5i2.2284

(C) 2021 Jurnal Lensa Mutiara Komunikasi. This is an open access article under the CC BY-SA license Website: http://e-journal.sari-mutiara.ac.id/index.php/JLMI

http://e-journal.sari-mutiara.ac.id 


\section{PENDAHULUAN}

Kerajinan bambu merupakan salah satu komoditas kerajinan unggulan di Jawa Barat. Lebih dari 100 pusat kerajinan bambu tersebar di empat wilayah di Jawa Barat, yakni Garut, Tasikmalaya, Ciamis dan Cianjur (bisnisbandung.com 2017). Berbagai jenis kerajinan bambu dengan beragam desain dan ukuran, dihasilkan oleh para pengrajin untuk keperluan rumah tangga, konstruksi, dekorasi, seni, hingga fashion, antara lain, kotak tisu, topi, tas, kursi, pot bunga, pembatas dinding, kap lampu, nampan, peci, dan sebagainya. Kerajinan bambu yang dihasilkan memiliki fungsi pakai dan fungsi dekoratif, yang menghiasi hotel, restoran, kantor maupun rumah tinggal (Lubis 2008)

Industri kerajinan bambu di Jawa Barat tumbuh alamiah secara turun temurun membentuk sentra-sentra pengrajin, yang memiliki keterampilan mengelola bambu yang diperoleh melalui proses belajar dari generasi sebelumnya. Faktor-faktor pendukung munculnya sentra kerajinan bambu di berbagai wilayah di Jawa Barat antara lain ketersediaan bambu di wilayah pengrajin serta masih adanya masyarakat yang memerlukan hasil olahan bambu untuk beragam keperluaun.

Sentra kerajinan bambu terbesar di Jawa Barat berada di Kabupaten Tasikmalaya, dan tersebar di Kecamatan Leuwisari, Salawu, dan Singaparna. Produksi kerajinan bambu dari Kabupaten Tasikmalaya mencapai sekira 7 juta unit per tahunnya dengan nilai mencapai Rp 26,94 miliar, yang berasal dari 34 sentra dan 1.500 unit usaha kerajinan bambu.

Pangsa pasar kerajinan bambu tetap bertahan di tengah banyaknya produk berbahan plastik yang harganya lebih murah. Harry Mawardi, dosen sekaligus pemilik Amygdala Bamboo, yang bermitra dengan pengrajin bambu di Selaawi, mengungkapkan, secara kualitas, hasil pekerjaan pengrajin bambu Selaawi tidak perlu diragukan lagi, karena sudah dikenal luas, terutama kerajinan sangkar burung, sebagai kerajinan bambu utama. Produk bambu kreatif yang dihasilkan oleh Amygdala Bamboo pun pemasarannya telah mencapai ke luar negeri, seperti Singapura, Korea Selatan, Italia, Australia dan Jepang.

Kerajinan bambu Tasikmalaya telah ada sejak lama. Hasil penelitian Gandjar Sakri mengungkapkan bahwa anyaman bambu uhalus di Tasikmalaya diciptakan oleh seorang petani-pengrajin Martadinata pada tahun 1890. Martadinata yang dikenal sebagai Haji Soheh, diangkat oleh Pemerintah Hindia Belanda pada tahun 1901 sebagai guru untuk menyebarluaskan jenis kerajinan tersebut ke wilayah Ngawi dan Nganjuk di Jawa Tengah serta Makassardi Sulawesi. Penyebaran di Tasikmalaya dilakukan setelah pemerintah Hindia Belanda memberlakukan etische politiek pada tahun 1904 (Sakri 2009)

Hingga kini, kerajinan bambu di Tasikmalaya terus bertahan, bahkan pemasarannya pun tidak hanya lokal, tapi berkembang hingga ke luar negeri.

Penelitian terdahulu mengenai kerajinan tradisional Tasikmalaya adalah "Strategi Pengembangan Usaha Kecil Menengah: Studi Kasus di Sentra Kerajinan Bambu (SKB) Putra Handicraft Kota Tasikmalaya, oleh Moh. Ferry Prihardiputra (2012). Melalui analisis SWOT, penelitian ini menghasikan temuan adanya faktor internal dan eksternal yang memengaruhi jalannya usaha kerajinan bambu di salah satu outlet di Tasikmalaya. Faktor internal terdiri dari enam faktor kekuatan dan lima faktor kelemahan. Empat faktor eksternal serta tiga faktor ancaman. Alternatif strategi prioritas, yaitu peningkatan kemampuan staf dan keterampilan perajin, serta pembuatan identitas perusahaan dengan bantuan tenaga kerja yang kreatif (Prihardiputra 2012) 
Dibandingkan dengan dua penelitian terdahulu, penelitian ini akan menggali lebih dalam mengenai strategi pemasaran kerajinan bambu dalam skala yang makro, yakni tidak terpusat pada satu sentra produksi saja, melainkan pada beberapa sentra produksi untuk kemudian ditarik benang merahnya. Strategi komunikasi pemasaran yang akan dikaji dalam penelitian ini dilandasi kearifan lokal, yang dimaksudkan sebagai komunikasi pemasaran produk-produk hasil kreasi masyarakat lokal hasil adaptasi terhadap lingkungan alam setempat. Hal ini penting diteliti, karena produk-produk tersebut merupakan kreatifitas masyarakat yang memberdayakan potensi di sekitarnya menjadi karya yang menjadi identitas masyarakat setempat agar dikenal lebih luas.

Penelitian ini dilakukan di Tasikmalaya, yang terdiri dari kota dan Kabupaten Tasikmalaya dengan tujuan untuk menemukan komunikasi pemasaran yang dilakukan pengusaha bambu di Tasikmalaya dalam memertahankan kelangsungan bisnis serta pengembangan produksi menjadi produk bernilai ekspor dan menjangkau pasar yang lebih luas, tidak hanya di sekitar Tasikmalaya.

Penelitian ini bertujuan untuk mengungkapkan perilaku komunikasi pelaku usaha kerajinan bambu kreatif di Tasikmalaya dalam mengembangkan bisnis lokal berorientasi pasar lokal, nasional dan ekspor.

\section{TINJAUAN LITERATUR}

\section{Komunikasi Pemasaran}

Komunikasi pemasaran didefinisikan sebagai sarana yang digunakan perusahaan untuk menginformasikan, memengaruhi dan mengingatkan konsumen mengenai produk yang dijual oleh perusahaan. Komunikasi pemasaran atau marketing communication merupakan sebuah metode yang dapat memajukan dan mengembangkan suatu lembaga pendidikan maupun sebuah organisasi, sehingga manajemen pemasaran yang baik harus diutamakan (Tsikirayi, Muchenje, and Katsidzira 2013).

Komunikasi pemasaran dilakukan melalui bauran komunikasi pemasaran (marketing communication mix), yang terdiri dari delapan model komunikasi utama yang diungkapkan Kotler \& Keller:

1. Iklan, yaitu semua bentuk berbayar dari presentasi non personal dan promosi ide, barang atau jasa melalui sponsor yang jelas.

2. Promosi penjualan, berbagai insentif jangka pendek untuk mendorong percobaan atau pembelian produk atau jasa.

3. Acara dan pengalaman, kegiatan dan program yang disponsori perusahaan yang dirancang untuk menciptakan interaksi harian atau interaksi yang berhubungan dengan merek tertentu.

4. Hubungan masyarakat dan publisitas, beragam program yang dirancang untuk mempromosikan atau melindungi citra perusahaan atau produk individunya

5. Pemasaran langsung, penggunaan surat, telepon, faximile, e-mail, atau internet untuk berkomunikasi secara langsung dengan meminta respons atau dialog dari pelanggan dan prospek tertentu.

6. Pemasaran interaktif, kegiatan dan program online yang dirancang untuk melibatkan pelanggan atau prospek secara langsung atau tidak langsung meningkatkan kesadaran, memperbaiki citra, atau menciptakan penjualan produk dan jasa. 
7. Pemasaran dari mulut ke mulut, komunikasi lisan, tertulis, dan elektronik antar masyarakat yang berhubungan dengan keunggulan atau pengalaman membeli atau menggunakan produk atau jasa (Kurnianti 2018).

\section{Integrated Marketing Communication}

Integrated Marketing Communication (IMC) merupakan suatu proses komunikasi yang memerlukan perencanaan, penciptaan, integrasi, dan implementasi dari berbagai bentuk marketing communication (iklan, promosi penjualan, publisitas perilisan, acara-acara, dll.) yang disampaikan dari waktu ke waktu kepada pelanggan target mereka dan calon pelanggan (Shimp 2014). Menurut Vargas, proses IMC yang efektif berkaitan dengan identifikasi audiens target, penentuan tujuan komunikasi, merancang isi pesan, memilih sarana untuk komunikasi, mendefinisikan campuran media, anggaran dan prioritas serta mengukur efektivitas usaha (Bilal et al. 2013).

Komunikasi yang efektif sangat membantu jalannya pesan yang disampaikan dan akan mendapatkan respon yang positif dari penerima pesan. Komunikasi pemasaran terpadu dilakukan agar mendapatkan segmentasi yang luas sehingga produk layanan pendidikan tersebut dipercaya oleh masyarakat. Schultz mendefinisikan IMC sebagai konsep perencanaan komunikasi pemasaran yang menggabungkan dan mengevaluasi peran strategis disiplin komunikasi yang berbeda untuk mendapatkan kejelasan, konsistensi dan dampak yang lebih besar (Bilal et al. 2013).

McCarthy mendefinisikan bauran komunikasi pemasaran sebagai gabungan dari iklan, personal selling, promosi penjualan, hubungan masyarakat, dan pemasaran langsung, perusahaan menggunakan iklan untuk mengejarnya dan tujuan pemasaran (Tsikirayi, Muchenje, and Katsidzira 2013). Bauran komunikasi pemasaran dapat memberikan dampak positif pada komunikasi, kreativitas dan sangat konsisten, serta dapat memberikan kontribusi nyata sebagai media promosi terpadu campuran dalam bidang komunikasi. Rehman dan Ibrahim menyebutkan, tujuan utama bauran komunikasi pemasaran adalah untuk memengaruhi persepsi nilai dan perilaku melalui komunikasi (Santoso 2018).

\section{Kearifan Lokal}

Kearifan lokal merupakan wujud adaptasi manusia terhadap alam sekitarnya dalam upaya pemenuhan kebutuhan hidupnya. Fajarini (dalam Susanti \& Sukaesih 2017), mengartikan kearifan lokal sebagai pandangan hidup dan ilmu pengetahuan serta berbagai strategi kehidupan yang berwujud aktivitas yang dilakukan oleh masyarakat lokal dalam menjawab berbagai masalah dalam pemenuhan kebutuhan mereka.

Wales menjelaskan bahwa kearifan lokal bersumber dari kebiasaan yang dilakukan oleh manusia dalam kehidupan sehari-hari ketika berinteraksi dengan alam sekitarnya. Bisa jadi kearifan lokal ini menjadi ciri kebudayaan yang dimiliki suatu masyarakat sebagai akibat pengalamannya di masa lalu (Budiwiyanto 2005).

Dalam konteks penelitian ini, budaya yang dimaksud adalah budaya lokal masyarakat Sunda dalam hubungannya dengan alam, yakni hutan bambu. Kearifan masyarakat lokal dalam menjalin hubungan dengan alam, umumya diidentikkan dengan wilayah pedesaan, yang memiliki kawasan hayati cukup luas. 
Bagi masyarakat Tasikmalaya yang menekuni kerajinan bambu, upaya kreatif mengubah bambu menjadi berbagai bentuk yang dapat dimanfatkan dalam kehidupan seharihari merupakan wujud adaptasi mereka untuk mempertahankan hidup dan menjadikan hasil kreatifitas mereka sebagai mata pencaharian yang dapat menghidupi mereka. Pengetahuan tentang kearifan lokal tersebut dipraktikkan, diajarkan dan diwariskan dari satu generasi ke generasi berikutnya.

\section{METODE PENELITIAN}

Penelitian ini menggunakan metode kualitatif dengan pendekatan studi kasus. untuk menelaah perilaku pemasaran yang digunakan oleh para pengrajin dalam mendistribusikan hasil karya mereka dari bambu. Dalam studi kasus, peneliti menggali data sebanyak mungkin agar dapat memberikan pandangan yang lengkap dan mendalam mengenai obyek yang diteliti (Mulyana 2010).

Dalam penelitian ini, peneliti menggali informasi dari informan yang relevan dengan fokus penelitian. Untuk itu pertanyaan penelitian lebih banyak berkaitan dengan why atau how (Yin 2011). Dalam penelitian ini, peneliti berupaya menggali secara mendalam mengenai strategi komunikasi pemasaran yang dilakukan pengrajin bambu di Tasikmalaya dalam mengembangkan usaha kerajinannya lebih dikenal oleh masyarakat, hambatan yang ditemui serta kesiapan potensi sumber daya manusia dalam mengembangkan inovasi produk serta perluasan pasar.

Penelitian dilakukan dengan mengunjungi langsung para pengrajin di Kota dan Kabupaten Tasikmalaya. Pengumpulan data dilakukan melalui wawancara, observasi, kajian pustaka dan studi dokumentasi yang berkaitan dengan penelitian. Wawancara dilakukan kepada para pengrajin atau pelaku usaha kerajinan bambu yang dipilih melalui purposive sampling, agar sesuai dengan tujuan penelitian (Bungin 2011). Teknik snowball sampling digunakan untuk memperoleh informan lainnya yang relevan dengan penelitian yang dilakukan.

Uji keabsahan data akan dilakukan melalui dengan triangulasi, kecukupan referensi dan pengecekan melalui diskusi. Diskusi dengan berbagai kalangan yang memahami masalah penelitian akan memberi informasi yang berarti bagi peneliti, sekaligus sebagai upaya untuk menguji keabsahan hasil penelitian (Bungin, 2011: 266).

Dalam penelitian ini, digunakan tiga komponen analisis data yaitu reduksi data, penyajian data dan penarikan kesimpulan, yang dikemukakan oleh Miles dan Huberman (Miles, Huberman, and Saldana 2014). Data yang diperoleh kemudian direduksi dengan cara dipilah dan dikategorikan sesuai dengan pertanyaan penelitian. Data yang telah dipilah disajikan secara deskriptif ke dalam bentuk narasi yang dilengkapi dengan kutipan dari nara umber. Setelah itu, data dianalisis dan ditarik kesimpulan yang menggambarkan hasil penelitian. Ketiga tahap analisis data tersebut dilakukan simultan dan terus menerus selama proses pengumpulan data di lapangan sehingga dapat disebut sebagai model interaktif.

\section{HASIL DAN PEMBAHASAN}

Tasikmalaya sendiri merupakan wilayah dengan sentra kerajinan bambu terbesar di Jawa Barat dengan 34 sentra kerajinan dan 1.567 unit usaha yang tersebar di Kecamatan 
Leuwisari, Salawu, dan Singaparna. Setiap tahun, produksi kerajinan bambu dari Kabupaten Tasikmalaya mencapai 6,96 juta unit, senilai Rp 26,94 miliar. (bisnisbandung.com, 2017).

Pengrajin bambu di Tasikmalaya terbagi di wilayah Kota dan Kabupaten Tasikmalaya. Sebagian besar pengrajin menekuni kerajinan anyaman bambu, baik anyaman kasar maupun anyaman halus. Anyaman kasar bambu dicirikan dari bahan bakunya berupa bambu serut yang masih kasar serta lebih banyak digunakan untuk keperluan rumah tangga yang ada di dapur, seperti tempat sampah, nyiru, tolombong (bakul yang besar) dan lainnya. Sedangkan anyaman halus, bahan bakunya diolah supaya permukaannya tidak kasar dan dalam praktiknya, serat bambunya kecil. Umumnya digunakan selain karena fungsinya, juga bisa sebagai barang hiasan, karena tampilannya yang diolah secara estetis. Anyaman bambu yang dihasilkan antara lain, dompet, tikar dinding, tas wanita, tas sekolah, map surat, topi dan sebagainya (Sakri, 2009).

Penelitian yang dilakukan Gandjar Sakri pada tahun 1973 menunjukkan bahwa anyaman bambu kasar terdapat di Kecamatan Leuwisari, Kawalu dan Cigalontang. Jenis anyaman bambu setengah halus terdapat di Situbeet, Mangkubumi, Kota Tasikmalaya, dan anyaman bambu halus terdapat di Kecamatan Ciawi, Rajapolah, Cisayong, Indihiang. Daerah kegiatan anyaman bambu halus adalah Kampung Parakanhonje, Desa Sukamaju Kaler, Kecamatan Indihiang, Kota Tasikmalaya (Sakri, 2009).

Berbeda dengan pengrajin di Kabupaten Garut, pengrajin di Tasikmalaya tidak berkelompok. Mereka tidak memiliki kelompok pengrajin. Hal ini disebabkan kondisi pengrajin yang keberadaanya tersebar, tidak berkelompok seperti di Selaawi. Selain itu, pengrajin bambu di Tasikmalaya tidak ada yang membuat sangkar burung maupun home décor.

Perilaku komunikasi dalam memasarkan produk bambu kreatif di Tasikmalaya, terdiri dari perilaku komunikasi internal dan perilaku komunikasi eksternal. Perilaku komunikasi internal dilakukan kepada orang-orang yang berada dalam lingkaran terdekat dari pelaku usaha kerajinan bambu. Komunikasi yang dijalankan adalah komunikasi yang bersifat kekeluargaan yang lebih mengutamakan komunikasi interpersonal dan kelompok kecil.

Perilaku komunikasi eksternal dilakukan oleh para pengrajin melalui tatap muka dan media online. Adapun bentuk perilaku komunikasi yang dijalani, terkait dengan pemasaran produk. Sifatnya lebih kepada perilaku komunikasi transaksional, yang ditujukan kepada calon pembeli maupun kepada penyedia barang. Sementara itu, komunikasi yang dilakukan kepada pemerintah, tidak semuanya melakukan. Umumnya, perilaku komunikasi yang dilakukan terhadap pemerintah, berkaitan dengan promosi produk, agar dikenal luas di masyarakat.

Dari segi pemasaran, para pengrajin di Tasikmalaya pun menggunakan cara online dan offline. Pemasaran offline dilakukan melalui penjualan kepada konsumen, umumnya dilakukan melalui pameran.

Bagi para pelaku ekonomi kreatif, seperti kerajinan dari bambu, pameran memiliki peran sangat penting dalam mengenalkan produk-produk yang dihasilkan oleh para pengrajin. Pameran memiliki beberapa manfaat, antara lain sebagai sarana pengenalan produk baru, mendapatkan calon pembeli, menghasilkan transaksi selama pameran, sebagai 
ajang menambah network, sebagai riset trend pasar, meningkatkan image dan visibilitas, serta belajar dari pembeli secara langsung

Secara online melalui media sosial. Beberapa media sosial yang kerap digunakan oleh para pengrajin Tasikmalaya dalam mempromosikan maupun memasarkan produknya, antara lain Facebook, Instagram, Whatsapp. Beberapa pengrajin di Tasikmalaya telah menggunakan Instagram untuk pemasaran produk anyaman bambunya.

Para pengrajin bambu di Tasikmalaya lebih banyak yang mandiri sehingga mereka tidak tergantung dengan bantuan pemerintah. Mereka masih bisa mengembangkan kerajinan mereka hingga ke luar daerah. Bagi para pengrajin bambu di Tasikmalaya, bambu merupakan salah satu bagian dari warisan budaya yang harus dilestarikan, karena menjadi ciri khas dari Tasikmalaya sebagai sentra kerajinan tangan di Jawa Barat.

Kreasi bambu yang dihasilkan pun beragam. Selain anyaman, ada juga bambu coating atau laminating, berupa cangkir, teko, home décor, peralatan rumah tangga (sendok, garpu, tatakan, rantang, dsb).

Penelitian ini juga menemukan adanya kesamaan dari pengrajin bambu di Tasikmalaya, yakni adanya proses regenerasi yang belangsung secara alamiah, tanpa ada pemaksaan kepada pewarisnya untuk meneruskan keterampilan yang dipelajarinya. Kerajinan bambu yang merupakan kreasi yang dihasilkan secara turun-temurun diajarkan secara langsung maupun tidak langsung dengan mengamati, maupun praktik langsung. Menurut penuturan beberapa pengrajin di Tasikmalaya, perilaku para pengrajin yang setiap hari membuat kreasi dari bambu, secara perlahan menarik perhatian dari anak-anak mereka untuk mencoba atau ikut terlibat dalam suatu projek pembuatan karya dari bambu. Melihat perilaku tersebut, para pengrajin senior merasa senang, karena anak-anak mereka terlihat ada ketertarikan pada kerajinan bambu, meski dalam praktiknya, mereka tidak mengharuskan anak-anaknya untuk terjun sebagai pengrajin bambu. Bagi para pengrajin, keinginan anakanaknya untuk terlibat dalam pekerjaan yang sedang mereka lakukan, membuat mereka merasa cukup. Keterampilanl yang mereka pelajari dapat menjadi bekal bagi anak-anak mereka kelak, saat mereka kesulitan untuk memperoleh pekerjaan sesuai yang mereka inginkan. Keterampilan mengolah bambu, dapat dijadikan tumpuan mata pencaharian bagi mereka.

\section{KESIMPULAN}

Kerajinan bambu di Tasikmalaya, tumbuh dan berkembang secara turun temurun, karena lingkungan masyarakatnya sebagian besar menekuni profesi sebagai pengrajin. Bagi sebagian besar pengrajin, faktor pemasaran dan modal menjadi kendala utama. Akan tetapi, bagi para pengrajin yang usahanya telah berkembang, pemasaran tidak hanya dilakukan secara konvensional melalui penjualan langsung. Teknologi internet dimanfaatkan sebagai sarana pemasaran melalui media sosialnya, seperti Facebook, Whatsapp, dan Instagram.

Perilaku komunikasi yang dijalankan para pelaku usaha bambu kreatif di terdiri dari perilaku komunikasi internal dan perilaku komunikasi eksternal. Perilaku komunikasi internal dilakukan kepada para pekerja dengan prinsip kekeluargaan. Sementara itu, bentuk perilaku komunikasi eksternal terkait dengan pemasaran produk. Bentuknya disesuaikan dengan pihak yang dihadapi oleh pelaku usaha. Bagi para pelaku usaha kerajinan bambu di 
Tasikmalaya, keterampilan mengolah bambu harus dimiliki oleh setiap generasi penerusnya sebagai bekal di masa depan.

\section{DAFTAR PUSTAKA}

Bilal, Muhammad, Rashid Saeed, Bilal Naeem, and Uzma Naz. 2013. "Integrated Marketing Communication: A Review Paper." Interdisciplinary Journal of Contemporary Research in Business 5 (5) (September): 124-33.

bisnisbandung.com. 2017. "Jabar Andalkan Industri Kreatif Bambu," 2017.

Budiwiyanto, Joko. 2005. "Tinjauan Tentang Perkembangan Pengaruh Local Genius Dalam Seni Bangunan Sakral (Keagamaan) Di Indonesia.” Ornamen 2 (1): 25-35.

Bungin, M. Burhan. 2011. Penelitian Kualitatif. Jakarta: Kencana Prenada.

Kurnianti, Apsari Wahyu. 2018. "Strategi Komunikasi Pemasaran Digital Sebagai.” Jurnal Riset Komunikasi 1 (1): 180-90.

Lubis, U. 2008. "Pasang Surut Industri Kerajinan Bambu Di Tasikmalaya Jawa Barat." Jurnal Dimensi 5 (1): 95-112.

Miles, Matthew B., A. Michael Huberman, and Johnny Saldana. 2014. Qualitative Data Analysis A Methods Sourcebook Edition 3. 3rd ed. California: SAGE Publications, Inc.

Mulyana, Deddy. 2010. Metodologi Penelitian Kualitatif (Paradigma Baru Ilmu Komunikasi dan Ilmu Sosial Lainnya). Bandung: Remaja Rosdakarya.

Prihardiputra, Moh. Ferry. 2012. "Strategi Pengembangan Usaha Kecil Menengah: Studi Kasus di Sentra Kerajinan Bambu (SKB) Putra Handicraft Kota Tasikmalaya."

Sakri, Gandjar. 2009. “Tinjauan Historis Perkembangan Kerajinan Tangan Anyaman Bambu Halus Tasikmalaya." Dimensi 7 (1): 127-148.

Santoso, Prasetya Yoga. 2018. "Transformasi Integrated Marketing Communication Di Era Digital." Jurnal Pustaka Komunikasi 1 (2): 313-26.

Shimp, T. A. 2014. Komunikasi Pemasaran Terpadu Dalam Periklanan dan Promosi. Jakarta: Salemba Empat.

Susanti, Santi, and Sukaesih. 2017. "Kearifan Lokal Sunda dalam Pemanfaatan Tanaman Berkhasiat Obat oleh Masyarakat Cipatat Kabupaten Bandung Barat." WACANA, $\begin{array}{lllll}\text { Jurnal Ilmiah } \quad \text { Ilmu } & \text { Komunikasi } & 16 & \text { (2): } 291 .\end{array}$ https://doi.org/10.32509/wacana.v16i2.55.

Tsikirayi, Catherine Mazwi R, Blessing Muchenje, and Zodeac Katsidzira. 2013. "Impact of Integrated Marketing Communications Mix (IMCM) in Small to Medium Enterprises (SMEs) in Zimbabwe as a Marketing Tool.” Research in Business and Economics Journal 7 (Imcm): 1-12.

Yin, Robert K. 2011. Case Study Research: Design and Methods (Applied Social Research Methods). Illinois: Sage Publication. 